\title{
PERBANDINGAN PENGISIAN KAPASITOR OLEH PIEZOELEKTRIK DENGAN BATERI
}

\author{
R. Gustav Rinaldi, Muhammad Anton Kuncoro, Yesiana Arimurti \\ Program Studi Pendidikan Fisika, Fakultas Keguruan dan Ilmu Pendidikan Universitas Sebelas Maret, \\ Jl. Ir. Sutami no 36 Kentingan Surakarta \\ Email : gustavrinaldi7@gmail.com
}

\begin{abstract}
This study aims to compare the charging of capacitors by piezoelectric with batteries. The research method is tapping a $2.7 \mathrm{~cm}$ diameter piezoelectric using a finger with a frequency of $30 \mathrm{bpm}$, $60 \mathrm{bpm}, 90 \mathrm{bpm}, 120 \mathrm{bpm}, 150 \mathrm{bpm}$ and $180 \mathrm{bpm}$ to fill a capacitor of $47 \mathrm{uF}$ which is observed every 10 seconds for 90 seconds. The 30, 60, 90, 120, 150, and $180 \mathrm{bpm}$ beats respectively produced the capacitor end voltage of $575 \mathrm{mV}, 882 \mathrm{mV}, 980 \mathrm{mV}, 1337 \mathrm{mV}, 1383 \mathrm{mV}$, and $1444 \mathrm{mV}$. After that, the relationship between the beat frequency and the final voltage of the capacitor is analyzed to be compared with charging the capacitor by the battery.
\end{abstract}

Keywords: piezoelectric, frequency, battery

\begin{abstract}
Abstrak: Penelitian ini bertujuan untuk membandingkan pengisian kapasitor oleh piezoelektrik dengan baterai. Metode peneltian berupa mengetuk sebuah piezoelektrik berdiameter $2,7 \mathrm{~cm}$ menggunakan jari tangan dengan frekuensi $30 \mathrm{bpm}, 60 \mathrm{bpm}, 90 \mathrm{bpm}, 120 \mathrm{bpm}, 150 \mathrm{bpm}$, dan 180 bpm untuk mengisi kapasitor sebesar $47 \mathrm{uF}$ yang tegangannya diamati setiap 10 detik selama 90 detik. Ketukan 30,60, 90, 120, 150, dan $180 \mathrm{bpm}$ secara berturut - turut menghasilkan tegangan akhir kapasitor sebesar $575 \mathrm{mV}, 882 \mathrm{mV}, 980 \mathrm{mV}, 1337 \mathrm{mV}, 1383 \mathrm{mV}$, dan $1444 \mathrm{mV}$. Setelah itu, hubungan antara frekuensi ketukan dan tegangan akhir kapasitor dianalsisis untuk dibandingkan dengan pengisian kapasitor oleh baterai.
\end{abstract}

Kata kunci: piezoelektrik, frekuensi, baterai

\section{PENDAHULUAN}

Energi merupakan hal pokok yang menopang kehidupan manusia di dunia. Motivasi manusia dalam pencarian energi baru didorong oleh situasi global yang mengindikasikan cadangan energi fosil di bumi semakin menipis karena sifatnya yang tak terbarukan. Sebagai alternatif keterbatasan energi fosil, manusia mencoba menciptakan suatu alat pemanen energi (energy harvesting). Piezoelectric dapat diaplikasikan untuk pemanen energi dengan memanfaatkan energi kinetik karena sifat bahan piezoelectric yang dapat mengubah kinetik menjadi listrik (Widodo, Kirom, \& Qurthobi, 2017).

Dalam praktiknya, piezoelektrik sering digunakan untuk mengisi baterai yang selanjutnya akan digunakan untuk keperluan yang sesuai. Beberapa alat telah dibuat untuk mengisi baterai menggunakan piezo elektrik seperti lantai piezoelektrik, polisi tidur piezoelektrik, pembangkit listik tenaga hujan, serta sebagai catu daya tambahan dalam mobil (Almanda, Dermawan, Ramadhan, Diniardi, \& Fajar, 2015; Hendriawan \& Happyanto, 2014; Widodo dkk., 2017; Yulia, Putra, Ekawati, \& Nugraha, 2016).

Terdapat beberapa variabel yang mempengaruhi kinerja piezoelektrik, salah satunya adalah frekuensi. Frekuensi berperan dalam seberapa banyak tegangan yang akan timbul dalam selang waktu tertentu (Damjanovic, 1997). 
Tujuan dari penelitian ini adalah melihat bagaimana perilaku piezoelektrik dalam mengisi kapasitor dalam beberapa frekuensi tertentu untuk dibandingkan dengan baterai. Sehingga dari penelitian ini, dapat diketahui kesetaraan antara piezoelektrik dan baterai dalam mengisi kapasitor.

Secara teori hubungan antara tegangan kapasitor terhadap waktu selama proses pengisian kapasitor mengggunakan baterai dirumuskan :

dimana :

$$
V_{c}=V_{s}\left(1-e^{-\frac{t}{R C}}\right)
$$

$V_{c} \quad$ : Tegangan pada kapasitor (volt)

$V_{s} \quad$ : Tegangan sumber (volt)

$t \quad:$ Waktu (sekon)

$R \quad$ : Resistansi (ohm)

C : Kapasitas kapasitor (farad)

Piezoelectric merupakan sebuah efek yang berkaiatan dengan tekanan mekanik dan elektrisitas. Terdapat dua efek piezoelektrik, yaitu efek langsung pezoelektrik (direct piezoelectric effect) dan efek tidak langsung piezoelektrik (indirect piezoelectric effect). Efek langsung piezoelektrik (direct piezoelectric effect) merupakan peristiwa dihasilkannya arus listrik dari deformasi bahan piezoelectric akibat dari tekanan mekanik, atau dengan kata lain terjadinya perubahan energi dari energi mekanik menjadi energi listrik. Kebalikannya adalah efek tidak langsung piezoelektrik (indirect piezoelectric effect), merupakan peristiwa deformasi bahan atau perubahan bentuk bahan akibat adanya medan listrik. Pada artikel ini akan fokus membahas tentang efek langsung piezoelektrik (direct piezoelectric effect). Besarnyaa tegangan yang dihasilkan sebanding dengan tekanan yang diberikan, sensitivitas bahan dan ketebalan bahan piezoelektrik. Frekuensi berpangaruh terhadap banyaknya energi yang dihasilkan dalam selang waktu tertentu.

\section{METODE PENELITIAN (Section style)}

Metode penelitan terdiri dari penyusunan rangkaian yang digunakan untuk memperoleh data tegangan kapasitor yang diisi oleh piezoelektrik pada frekuensi tertentu serta analisis data untuk menemukan padanan baterai yang sesuai.

\subsection{Susunan Rangkaian}

Dalam penelitian ini, piezoelektrik yang digunakan adalah sebuah piezoelektrik berukuran kecil berbentuk lingkaran dengan diamter $2,7 \mathrm{~cm}$. Selanjutnya, piezoelektrik tersebut dihubungkan dengan dioda penyearah full bridge dan kapasitor sebesar $47 \mu \mathrm{F}$ yang akan diisi muatannya.

Dalam pengambilan data, piezoelektrik diketuk menggunakan jari telunjuk dengan frekuensi yang berbeda - beda selama 90 detik. Frekuensi yang digunakan adalah $30 \mathrm{bpm}, 60$ bpm. 90 bpm, 120 bpm, 150 bpm, dan 180 bpm. Dari ketukan - ketukan tersebut, tegangan pada kapasitor dicatat menggunakan voltmeter setiap 10 detik. Gambar pengambilan data percobaan dapat dilihat pada Gambar 1 . 


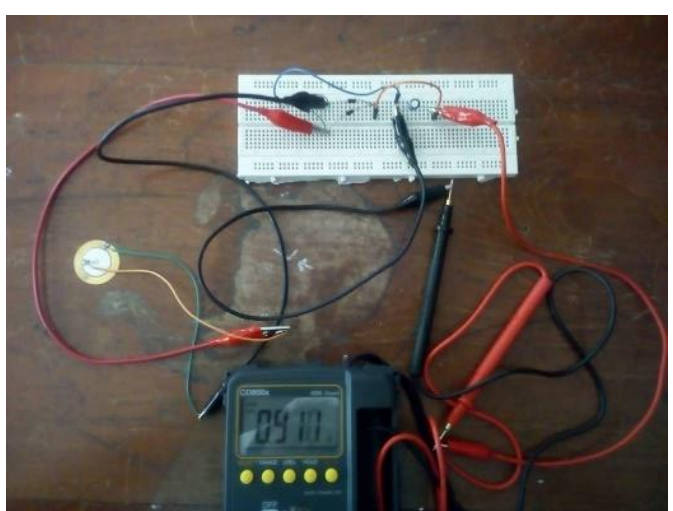

Gambar 1. Gambar rangkaian

\subsection{Metode Analisis Data}

Setelah data diperloeh, data dianalisis menggunakan Microsft Excel untuk menemukan padanan baterai yang sesuai ketika piezo diketuk dengan frekuensi tertentu. Untuk menemukan variabel dari persamaan non-linier, analisis dalam Excel dibantu dengan Add-Ins Solver.

\section{HASIL DAN PEMBAHASAN}

\subsection{Data}

Data penelitian untuk setiap frekuensi ketukan dapat dilihat pada Tabel 1.

Tabel 1. Tabel data penelitian tegangan kapasitor setiap satuan waktu dengan frekuensi beragam

\begin{tabular}{ccccccc}
\hline \multirow{2}{*}{$\begin{array}{c}\text { Waktu } \\
\text { (s) }\end{array}$} & \multicolumn{6}{c}{ Tegangan $(\mathbf{V})$} \\
\cline { 2 - 7 } $\mathbf{0}$ & $30 \mathrm{bpm}$ & $60 \mathrm{bpm}$ & $90 \mathrm{bpm}$ & $120 \mathrm{bpm}$ & $150 \mathrm{bpm}$ & $180 \mathrm{bpm}$ \\
\hline $\mathbf{1 0}$ & 0 & 0 & 0 & 0 & 0 & 0 \\
\hline $\mathbf{2 0}$ & 0,0926 & 0,149 & 0,195 & 0,219 & 0,256 & 0,272 \\
\hline $\mathbf{3 0}$ & 0,2281 & 0,3629 & 0,433 & 0,56 & 0,612 & 0,623 \\
\hline $\mathbf{4 0}$ & 0,29 & 0,429 & 0,53 & 0,695 & 0,784 & 0,808 \\
\hline $\mathbf{5 0}$ & 0,3614 & 0,53 & 0,631 & 0,825 & 0,929 & 0,941 \\
\hline $\mathbf{6 0}$ & 0,415 & 0,631 & 0,71 & 0,922 & 1,061 & 1,065 \\
\hline $\mathbf{7 0}$ & 0,464 & 0,731 & 0,79 & 1,056 & 1,202 & 1,195 \\
\hline $\mathbf{8 0}$ & 0,524 & 0,825 & 0,883 & 1,208 & 1,295 & 1,331 \\
\hline $\mathbf{9 0}$ & 0,575 & 0,882 & 0,98 & 1,337 & 1,383 & 1,444 \\
\hline
\end{tabular}

Dari Tabel 1, data digambarkan dalam bentuk grafik pada Gambar 2 


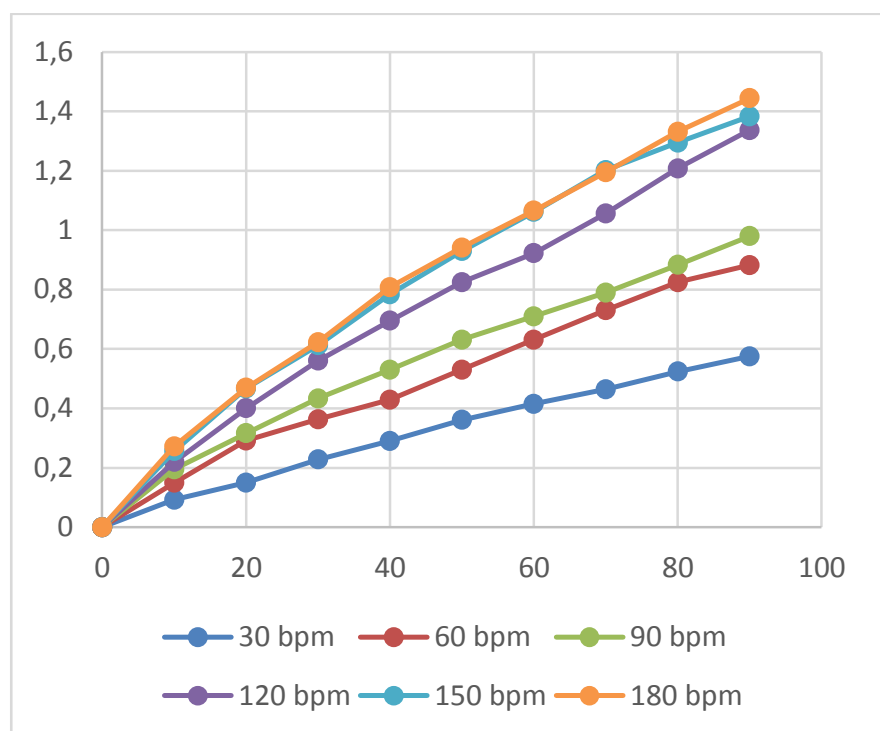

Gambar 2. Grafik teganan kapasitor setiap satuan waktu denga frekuensi beragam

\subsection{Hasil analisis kuantitatif}

Pengisian kapasitor dengan piezoelektrik diujicobakan menggunakan model matematika pengisian kapaitor oleh baterai sehingga diperoleh tegangan baterai yang setara. Dengan kapasitor sebesar $47 \mu \mathrm{F}$ dan hambatan antara piezoelektrik dan kapasitor adalah 10,5 $\mathrm{M} \Omega$, menggunakan Excel diperoleh hasil analisis yang ditunjukkan pada Tabel 2

Tabel 2. Tegangan baterai yang setara untuk setiap frekuensi

\begin{tabular}{ccc}
\hline Frekuensi (bpm) & Tegangan (Volt) & Standar deviasi \\
\hline $\mathbf{3 0}$ & 0,575577827 & 0,031647915 \\
\hline $\mathbf{6 0}$ & 0,896907163 & 0,046521215 \\
\hline $\mathbf{9 0}$ & 1,009199218 & 0,03312765 \\
\hline $\mathbf{1 2 0}$ & 1,310536214 & 0,05948792 \\
\hline $\mathbf{1 5 0}$ & 1,508111516 & 0,047857785 \\
\hline $\mathbf{1 8 0}$ & 1,513797129 & 0,050224543
\end{tabular}

Sedangkan, untuk visualisasi pada setiap frekuensinya, dapat dilihat pada Gambar 3 -

\section{Gambar 8}




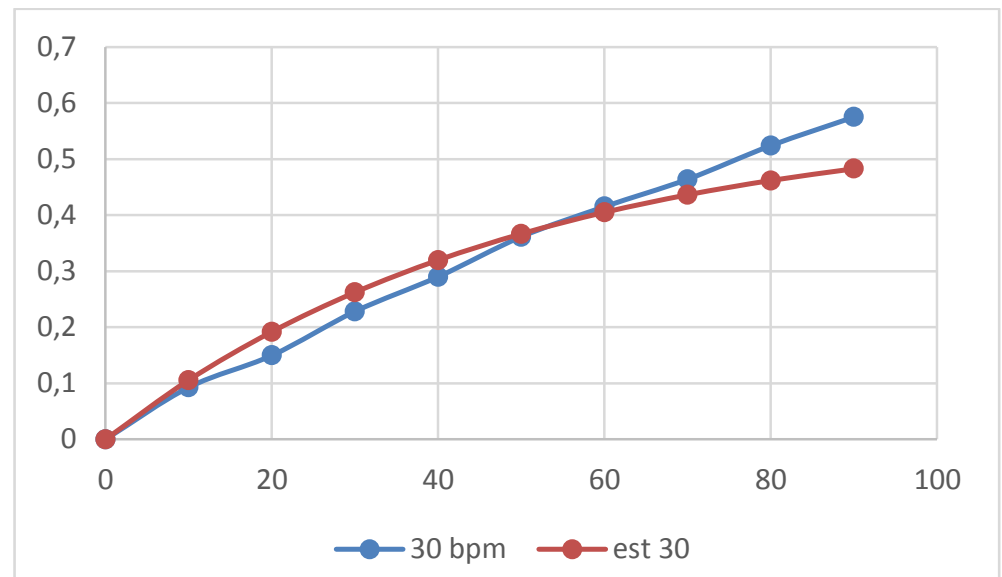

Gambar 3. Grafik menggunakan tegangan yang setara pada $30 \mathrm{bpm}$

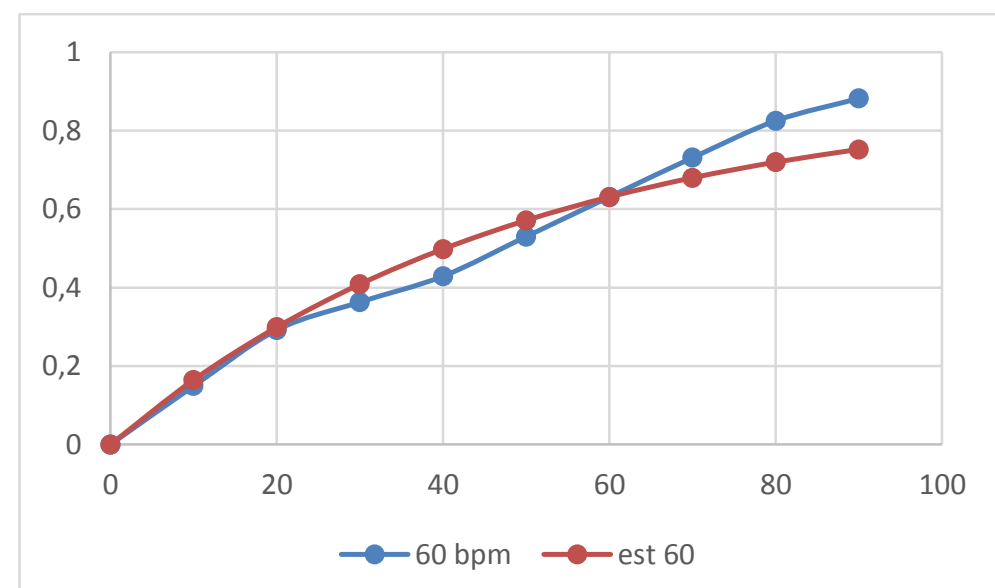

Gambar 4. Grafik menggunakan tegangan yang setara pada $60 \mathrm{bpm}$

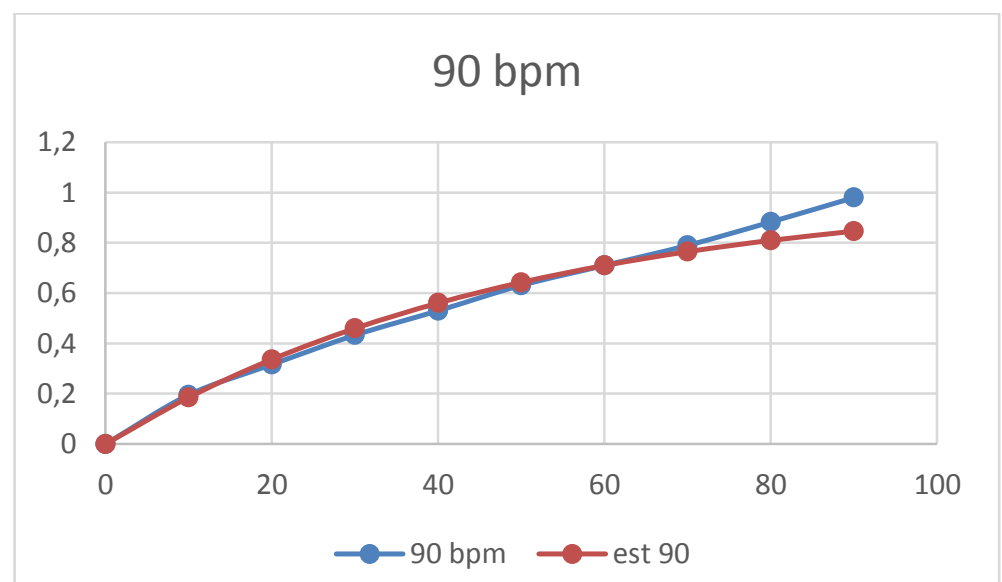

Gambar 5. Grafik menggunakan tegangan yang setara pada 90 bpm 


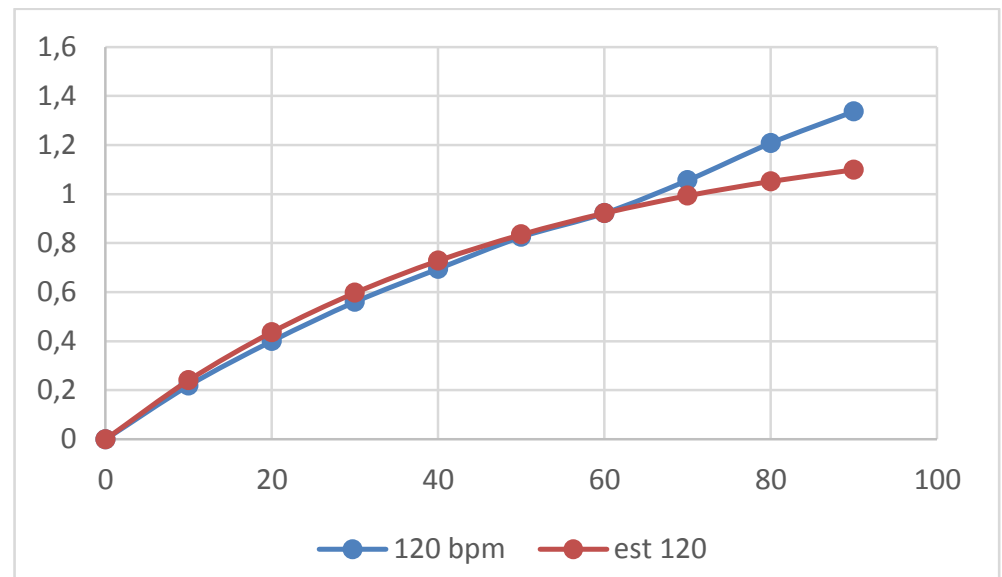

Gambar 6. Grafik menggunakan tegangan yang setara pada 120 bpm

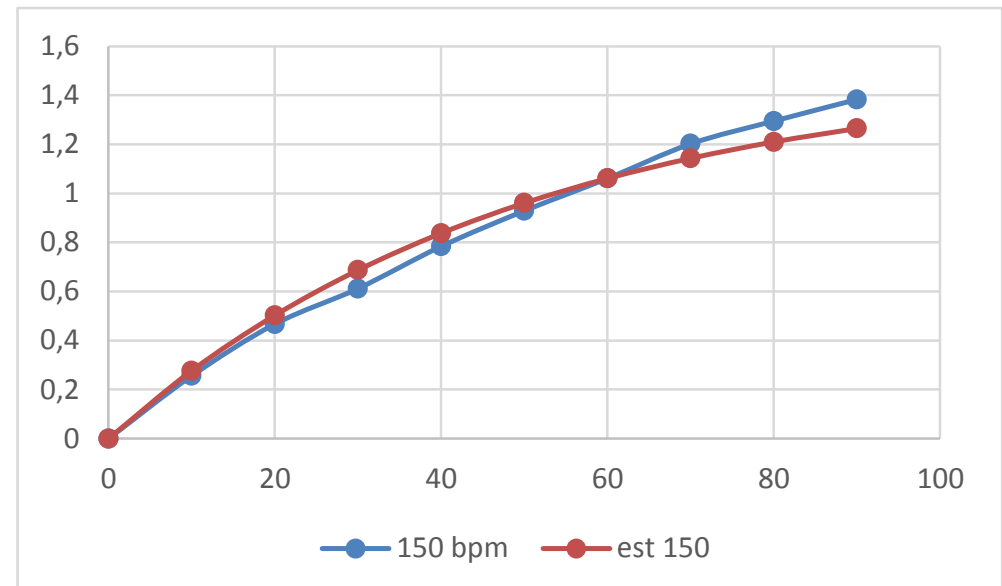

Gambar 7. Grafik menggunakan tegangan yang setara pada $150 \mathrm{bpm}$

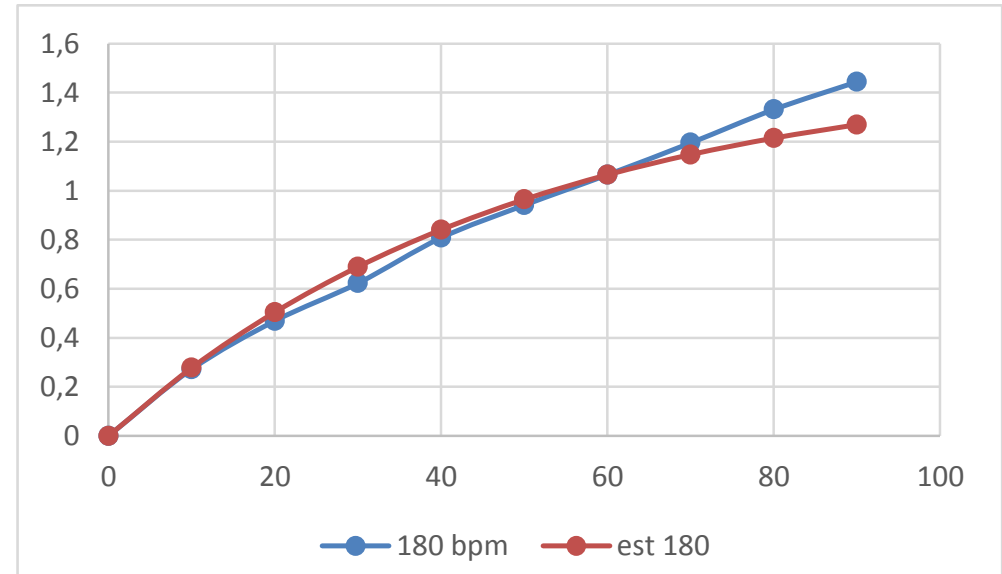

Gambar 8. Grafik menggunakan tegangan yang setara pada 180 bpm 


\subsection{Pembahasan}

Pada saat pengisian kapasitor terdapat dua besaran tagangan, yaitu besar tegangan sumber $\left(V_{s}\right)$ yang nilainya relatif tetap dan besar tegangan yang dimiliki kapasitor $\left(V_{c}\right)$ yang nilainya selalu berubah-ubah terhadap waktu. Dari hasil penelitian dapat kita lihat bahwa besarnya nilai $\left(V_{c}\right)$ dari masing-masing frekuensi dapat diketahui melalui pengukuran tegangan terhadap kapasitor. Dari tabel hasil, dapat diamati bahwa besarnya nilai tegangan kapasitor ini $\left(V_{c}\right)$ sebanding dengan besarnya frekueni ketukan yang diberikan.

Untuk mencari nilai $V_{S}$ maka digunakan perhitungan menggunakan persamaan $V_{c}=V_{s}\left(1-e^{-\frac{t}{R C}}\right)$ dan dibantu dengan Add-Ins Solver pada Microsoft Excell. Untuk masingmasing pengisian selama 90 detik, didapatkan hasil untuk frekuensi $30 \mathrm{bpm}$ mampu menghasilkan tegangan sebesar 0,575 volt, frekuensi $60 \mathrm{bpm}$ menghasilkan 0,896 volt, frekuensi $90 \mathrm{bpm}$ menghasilkan 1,009 volt, frekuensi $120 \mathrm{bpm}$ menghasilakn 1,310 volt, frekuensi $150 \mathrm{bpm}$ menghasilkan 1,508 volt dan frekuensi $180 \mathrm{bpm}$ menghasilkan 1,513 volt. Berikut adalah grafik hasil perhitungan :

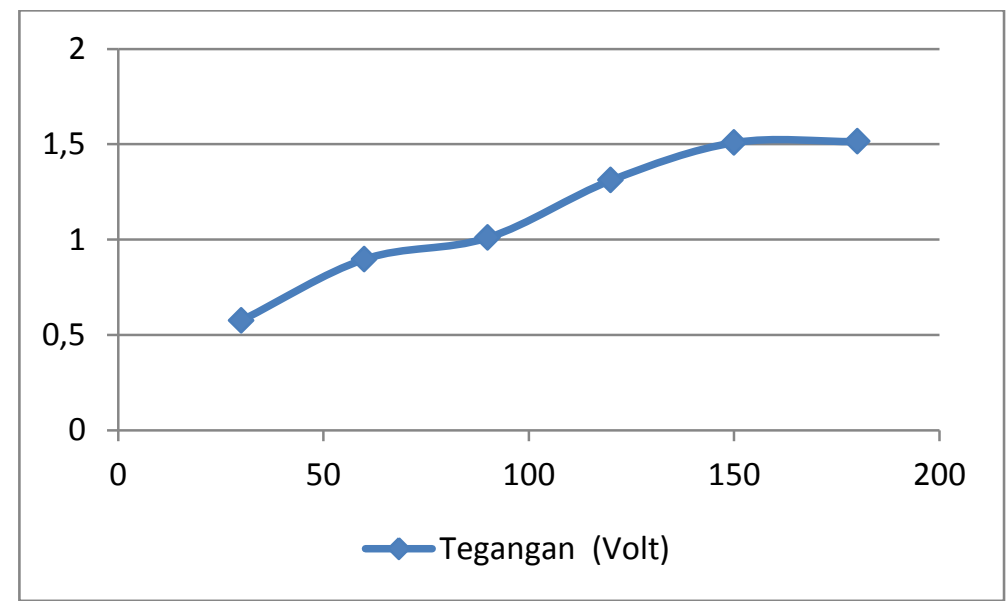

Gambar 9. Grafik hubungan frekuensi (bpm) terhadap tegangan (volt)

Berdasarkan grafik diatas, besarnya tegangan semakin besar sebanding dengan besarnya frekuensi. Secara rata-rata kenaikan tegangan yang signifikan ditunjukkan dari frekuensi 30 bpm ke $60 \mathrm{bpm}$, frekuensi $90 \mathrm{bpm}$ ke $120 \mathrm{bpm}$, dan $120 \mathrm{bpm}$ ke $150 \mathrm{bpm}$. Namun dari frekunsi $150 \mathrm{bpm}$ ke $180 \mathrm{bpm}$ terlihat bahwa kenaaikannya tidak terlalu signifikan. Hal tersebut terjadi karena kapasitor mendekati keadaan tunak (steady) - nya. Nilai deviasi menyatakan selisih antara tegangan kapasitor saat waktu tertentu terhadap tegangan sumber saat waktu yang sama.

Secara sekilas dapat dikatakan bahwa karakteristik penngisian kapasitor baik menggunakan baterai maupun menggunakan piezoelektrik adalah sama. Perbedaannya terletak pada karakteristik arus yang masuk ke kapasitor. Pada pengisian menggunkan batu bataerai, arus listrik masuk ke kapasitor secara kontinu dan suatu saat akan bernilai nol ketika tegangan pada kapasitor sama dengan tegangan baterai. Sedangkan, pada pengisian menggunakan piezoelektrik, karakteristik arus yang masuk ke kapasitor bersifat diskret atau terputus-putus. Hal tersebut terjadi karena tegangan yang dihasilkan oleh piezoelektrik bersifat fluktuatif tergantng besarnya tekananan yang diberikan.

Karena karakteristik tegangan output baterai yang lebih stabil, maka baterai tetap lebih cocok digunakan sebagai sumber catu daya daripada piezoelektrik. Pada beberapa sistem 
pembangkit listrik menggunakan piezoelektrik, kapasitor berfungsi sebagai penampung tegangan sementara yang berfungsi untuk menstabilkan tegangan yang akan dihubungkan ke baterai.

\section{KESIMPULAN}

Dalam selang waktu yang sama, besarnya nilai tegangan yang dihasilkan piezoelektrik sebanding dengan besarnya frekuensi ketukan mekanik yang diberiakan pada piezoelektrik. Perbedaan pengisian kapasitor menggunakan piezoelektrik dan baterai terletak ada karakteristik tegangan yang masuk ke kapasitor. Pada pengisian kapasitor menggunakan piezoelektrik tegangan yang masuk bersifat fluktuatif tergantung besar dan frekuensi ketukan mekanik. Sedangkan pada pengisian menggunakan batu baterai tegangan yang masuk ke kapasitor lebih stabil dan kontinu.

\section{SARAN}

Dari peneltian yang sudah dilakuakan., penulis memberikan saran agar dilakukan peneliitian lebih lanjut mengenai karakteristik tegangan yang dikeluarkan oleh piezolelektrik dengan melihat grafik gelombang tegangan yang dihasilkan. Selain itu, metodologi penelitian lebih dimantapkan lagi dengan beban pengetuk yang terukur nilainya.

Lebih lanjut lagi, penelitian dalam rangka komparasi anatara piezoelektrik dan baterai dapat dilakukan untuk menyelidiki konfigurasi seri-pararell piezoelektrik dibandingkan konfigurasi seri-pararel baterai. Metodologi dapat dilakukan dengan memberikan rectifier pada masing-masing piezoelektrik maupun satu rectifier untuk satu rangkaian seri-pararel piezoelektrik.

\section{DAFTAR PUSTAKA}

Almanda, D., Dermawan, E., Ramadhan, A. I., Diniardi, E., \& Fajar, A. N. (2015). Analisis Optimum Model Piezoelektrik PVDF untuk Sumber Pembangkit Listrik Air Hujan Berskala Mini. Dalam Prosiding Semnastek (Vol. 19, hlm. 1-5). Jakarta: Fakultas Teknik Universitas Muhammadiyah Jakarta.

Damjanovic, D. (1997). Stress and frequency dependence of the direct piezoelectric effect in ferroelectric ceramics. Journal of Applied Physics, 82(4), 1788-1797. https://doi.org/10.1063/1.365981

Hendriawan, A., \& Happyanto, D. C. (2014). Piezoelectric Sebagai Alternatif Catu Daya Tambahan pada Mobil Listrik. Invotek Polbeng, 4(1), 26-33.

Widodo, F. H., Kirom, M. R., \& Qurthobi, A. (2017). Perancangan Sistem dan Monitoring Sumber Arus Listrik dari Lantai Piezoelectric untuk Pengisian Baterai. Dalam eProceeding of Engineering (Vol. 4, hlm. 1). Telkom University: Telkom University.

Yulia, E., Putra, P., Ekawati, E., \& Nugraha. (2016). Polisi Tidur Piezoelektrik Sebagai Pembangkit Listrik dengan Memanfaatkan Energi Mekanik Kendaraan Bermotor. Jurnal Otomasi Kontrol dan Instrumentasi, 18(1), 105-113. 